\title{
Understanding the Characteristics and Staling of "Pan de Muerto": A Traditional Mexican Bread by Relating Its Fat Content to Starch Retrogradation
}

\author{
Anne Matignon ${ }^{1,2}$, Alberto Tecante ${ }^{1 *}$ \\ ${ }^{1}$ Departamento de Alimentos y Biotecnología, Facultad de Química, Universidad Nacional Autónoma de México (UNAM), CdMx \\ (Mexico City), Mexico \\ ${ }^{2}$ Roquette Frères, rue de la Haute Loge, Lestrem, France \\ Email: ^tecante@unam.mx
}

How to cite this paper: Matignon, A. and Tecante, A. (2021) Understanding the Characteristics and Staling of "Pan de Muerto": A Traditional Mexican Bread by Relating Its Fat Content to Starch Retrogradation. Food and Nutrition Sciences, 12, 509-525. https://doi.org/10.4236/fns.2021.126039

Received: May 10, 2021

Accepted: June 15, 2021

Published: June 18, 2021

Copyright $\odot 2021$ by author(s) and Scientific Research Publishing Inc. This work is licensed under the Creative Commons Attribution International License (CC BY 4.0).

http://creativecommons.org/licenses/by/4.0/

\begin{abstract}
"Pan de Muerto" is a traditional bread type, emblematic of Mexican bakery. This work's objectives were defining its characteristics, determining the effect of fat content, fat type, and storage conditions on its staling, and examining the relative impact of these conditions on fat crystallization and starch retrogradation. Staling was evaluated via changes in Young's modulus. Fat crystallization and starch retrogradation were studied considering the thermal and crystalline properties of unmodified and freeze-dried-defatted crumb. This bread is a hybrid of bakery and pastry products. Fat type, fat proportion, and storage conditions resulted in different staling behaviors not directly dependent on water content. Only butter crystallization depended on storage conditions. Starch retrograded over eight days of storage. The starch crystals' properties depended on fat content, whereas storage conditions impacted the rate of retrogradation. New relations between fat content and starch retrogradation are shown.
\end{abstract}

\section{Keywords}

Bread, Pan de Muerto, Starch, Staling, Texture, Wheat

\section{Introduction}

Baked cereal products (BCPs) are solid foams formed basically by crust and crumb. BCPs are heterogeneous and unstable [1] [2]. After baking and storage, they change in several ways that finally result in staled products. Staling has been 
defined as a decrease in consumer acceptance caused by changes other than microbiological spoilage, for instance, loss or modification of aroma and increase in hardness [3]. The increase in hardness is typically used to quantify staling and is significantly affected by storage conditions such as temperature or packaging [1] [4] [5] [6]. Starch retrogradation, water migration inside the product and between its components, evolution with time of protein, and the formation of protein-starch networks are considered the critical phenomena in staling [1] [2]. However, there is no consensus about the relative importance of these events to explain crumb firmness's evolution, but the relative impact of starch retrogradation was high in bakery products and low in pastry ones [2].

Starch is composed of porous semi-crystalline granules containing packed amylose and amylopectin. The crystalline array of starch produces X-ray diffraction patterns that depend on the botanical source; A-type for cereals and B-type for tubers [7]. When starch granules are heated in excess water, they lose their crystalline order, gelatinize, and swell irreversibly above the gelatinization temperature. In BCPs, starch gelatinization is mainly taken for granted [2]; however, it can be complete or not [8] [9]. Gelatinized starch is in an amorphous state, and only V-type crystals are detected. These crystals represent single helices of amylose complexed with endogenous starch lipids or added lipids [7] [10]. During storage, the molecular components of starch tend to reorganize themselves, leading to gel formation, starch crystallization, or both. All these phenomena are called retrogradation [11] [12] [13]. Amylose and amylopectin, pure or mixed, can form the same type of crystals. In the crumb of bakery and pastry products, only B-type crystals have been reported. Despite obtaining the same crystal types, those of "pure" amylose and amylopectin have very different thermal characteristics; they melt at temperatures between $120^{\circ} \mathrm{C}-150^{\circ} \mathrm{C}$ and below $100^{\circ} \mathrm{C}$, respectively [14].

The presence of lipids in the formulation of BCPs is said to limit staling. In addition, lipids influence the decrease of starch retrogradation by forming complexes with amylose and amylopectin, the limitation of water movement, and a positive impact on bread density [10]. Lipid crystals polymorphism could also allow different bread characteristics to be obtained [8]. However, this aspect and the impact of a high concentration of fat have not been sufficiently studied. "Pan de Muerto," literally "Bread of Dead," is a traditional seasonal product consumed in many parts of Mexico shortly before and after All Saints' Day on the $1^{\text {st }}$ of November. This bread is part of deeply rooted culinary and ritual traditions related to honoring deceased persons. In addition, it is said to have a long shelf life resulting from its formulation and, to a lesser extent, by storage conditions. However, the way its staling is affected by these two factors is not known.

BCPs have been separated into bakery products, consisting of flour, water, salt, yeast with or without secondary components such as fats or sugars, and pastry products, composed of high proportions of these secondary components and leavening agents [15]. "Pan de Muerto" mainly consists of flour, sugar, eggs, 
fat, and yeast. Therefore, it seems intermediate between bakery and pastry products. However, to the best of our knowledge, this type of bread has not been studied. The product is relevant because it is composed of a high fat/starch ratio combined with a gluten network. Systems of this type have not been reported in the literature. Also, the study of this product is scientifically relevant because it could contribute to the understanding of other traditional ones, e.g., French brioche.

The objectives of this work were, 1) to define the characteristics of "Pan de Muerto" and its place among products reported in the literature, 2) to obtain different staling rates by setting up distinct formulations and storage conditions, and 3) to identify the conditions with the most substantial impact on staling with a focus on starch retrogradation.

\section{Materials and Methods}

\subsection{Materials}

Materials included wheat flour (Harinera La Espiga, S.A. de C.V., Mexico; 15.0\% moisture, $10.5 \%$ protein, and $1.6 \%$ fat), fresh eggs (local market), refined sugar (sucrose) (local market), lard (local market), butter (Gloria, México; 15\% water and approximately $80 \%$ fat), whole pasteurized and homogenized milk (Lala, México) and fresh baker's yeast (La Florida, Mexico).

\subsection{Breadmaking}

A typical "Pan de Muerto" is shown in Figure 1. The primary formula, designated as control, is $100 \%$ flour, $57.3 \%$ whole egg, $35 \%$ sugar, $25 \%$ lard, $10 \%$ butter, $20 \%$ milk, and 1.5\% yeast. Other combinations included 35\% lard (Ld), 35\% butter (Bt), and without added fat (N.F.). In addition, some crumb samples were freeze-dried and defatted. Therefore, the designations normal and freeze-dried-defatted can be applied to control and modified formulas.

\subsection{Conditions}

The control was used to achieve objective 1 and allowed two conditions to be

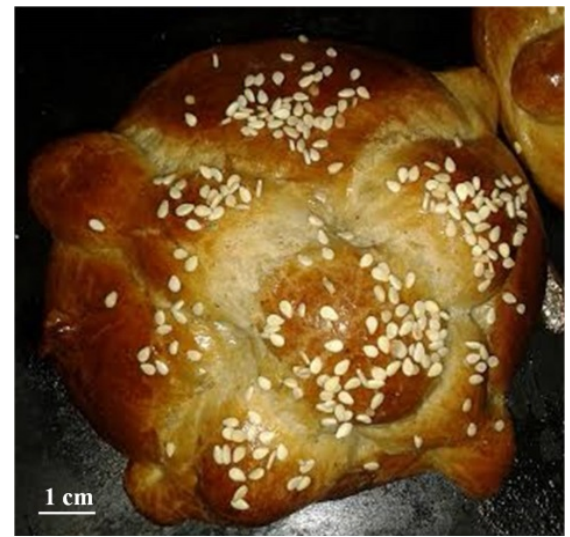

Figure 1. Top view image of "Pan de Muerto". 
defined to reach objective 2. Finally, objective 3 was attained by studying those two conditions: aging of bread stored in cardboard boxes at $20^{\circ} \mathrm{C}$ and plastic bags at $20^{\circ} \mathrm{C}$ and $4^{\circ} \mathrm{C}$ and modifying the fat type, lard or butter, and fat content 0 or $35 \%$ for each type.

\subsection{Preparation}

The ingredients were mixed at $\approx 20^{\circ} \mathrm{C}$ in a blender (Professional 600 , Kitchen-Aid, USA) using the flat beater at position 2 of the speed control for $5 \mathrm{~min}$ and position 4 for $5 \mathrm{~min}$, and subsequently with the spiral dough hook at position 2 for $5 \mathrm{~min}$. The resulting dough was fermented in a controlled-temperature chamber (Model 132,000, Boekel Scientific, USA) at $30^{\circ} \mathrm{C}$ for approximately 2.5 h. Then, dough balls of about $70 \pm 2 \mathrm{~g}$ were proofed during $25-35 \mathrm{~min}$ and baked in an electrical oven (KF 620, Eka, Italy) at $180^{\circ} \mathrm{C}$ for $15 \mathrm{~min}$. The resulting bread specimens were cooled to ambient temperature. Finally, the fresh pieces of bread were packed as indicated previously.

\subsection{Measurements}

For each ingredient's combination and storage condition, bread samples were assessed after baking (D0) and after one (D1), three (D3), and eight days of storage (D8). For the first part of the study, involving the control, only storage in cardboard boxes at $20^{\circ} \mathrm{C}$ was considered. The product stored at $4^{\circ} \mathrm{C}$ was first equilibrated at room temperature for one hour. Next, the crust was separated from the crumb using a kitchen knife. Four cubes of $(20 \times 20) \mathrm{mm} \pm 2 \mathrm{~mm}$ were cut out. The remaining crumbs were grounded and divided into two parts. One part, called normal crumb, was kept without further treatment and the other part, called freeze-dried-defatted crumb, was freeze-dried, and its fat was extracted using ethyl ether with a 1:15 (w/v) crumb to solvent ratio. The removal of fat was evaluated qualitatively from DSC and X-ray measurements.

\subsection{Moisture Content and Water Activity}

Moisture content and water activity were measured on normal crumb with a moisture analyzer ( $M B$ 45, Ohaus, Switzerland) and an Aw-quick instrument (Rotronic Instrument Corp, Switzerland).

\subsection{Mechanical Properties}

Particular attention was paid to compress the crumb in the same directions [16]. The specimens' mechanical properties at D0 and D3 for the cardboard boxes' storage condition could not be measured because the crumb was very soft and very crumbly, respectively. The cubes cut out from the crumb were compressed with a cylindrical aluminum probe $25 \mathrm{~mm}$ in diameter using a $100 \mathrm{~N}$ load cell (SINTECH 1/S, MTS, USA), at a speed of $1 \mathrm{~mm} / \mathrm{s}$ until $80 \%$ deformation. The recorded force-deformation responses were transformed to stress $(\mathrm{Pa})$-Hencky strain (\%) curves considering each cubic sample's dimensions. The apparent 
Young's modulus and the critical stress values were determined [16]. The critical stress was determined as the curve's tangent between regions I and II; Figure 2 (a). For each condition, Young's modulus determined at D1 was used to calculate its relative time evolution.

\subsection{Differential Scanning Calorimetry}

Normal and freeze-dried-defatted crumb samples were weighted into standard Hastelloy cells, and deionized water was added at 1:1 and 3:2 (w/w), respectively. The reference cell was filled with deionized water. Tests were run in a calorimeter ( $\mu$ DSC 7 EVO, Setaram, France). Each sample was equilibrated at $20^{\circ} \mathrm{C}$ for 10 min. Subsequently, it was heated and cooled from $5^{\circ} \mathrm{C}$ to $120^{\circ} \mathrm{C}$ and $120^{\circ} \mathrm{C}$ to $5^{\circ} \mathrm{C}$, respectively, at a rate of $1.0^{\circ} \mathrm{C} / \mathrm{min}$. Signals were analyzed using commercial software (Origin ${ }^{\circledR}$, OriginLab Corporation, USA). Enthalpies were expressed in $\mathrm{J} / \mathrm{g}$ of dry matter. The variation of average enthalpies was $\pm 0.02 \mathrm{~J} / \mathrm{g}$.

\subsection{X-Ray Diffraction}

Wide-angle X-ray diffraction measurements of normal and freeze-dried-defatted crumbs were performed in an X-ray spectrometer (D8 Advance, Bruker, Germany) at room temperature and under low humidity. The $\mathrm{X}$-ray generator irradiated the sample with $\mathrm{Cu} / \mathrm{Ka}$ radiation, wavelength $=0.154 \mathrm{~nm}$, and a copper tube operating at $40 \mathrm{kV}$ and $40 \mathrm{~mA}$. The scattering angle $(2 \theta)$ was $2-40$ with an angular path of $0.9 \mathrm{~s}$. Data were treated with the calorimeter software (Calisto, Setaram, France). Scattering signals in the range of 6 - 25 degrees were examined, smoothed; their total area was defined and finally normalized on the baseline. The peaks were delimited and associated with their starch crystal types [17]. The addition of the different areas of the peaks is called here the crystalline fraction. The peaks related to one type of starch crystal were then added and expressed relatively to the crystalline fraction.

\subsection{Data Analysis}

A one-way ANOVA and t-Test with two samples assuming equal variances were performed using Microsoft Excel $^{\circledR}$ 2010. Differences between treatment means were separated by Fisher's protected least significant test at the 0.05 probability level.

\section{Results and Discussion}

Pastry products typically contain higher fat levels than bread [3] [15]. Their moisture content is also in the range of $18 \%$ to $28 \%$ [2]. The formula of "Pan de Muerto" includes $35 \%$ fat, and its moisture content was $29 \% \pm 2 \%$ and $22.5 \% \pm$ $0.5 \%$ at D0 and D1, respectively. These two features make "Pan de Muerto" closer to pastry products. Furthermore, the crust of this bread was as easy to break as the crumb of cakes, and the sugar content in its formulation is three times lower than most of the reported cakes [2] [8] [9]. Also, the dough's gluten 
network is characteristic of bakery products because, in pastry ones, this network's development is limited [2]. These features can be identified as closer to bread. Therefore, "Pan de Muerto" attributes make it a hybrid between bread and pastry products. Hence, it was necessary to determine the freshly baked product's characteristics and their change with time during storage. In this way, it was possible to identify those factors distinctive of its formula and storage conditions that have a remarkable influence on staling.

\subsection{Mechanical, Thermal, and Crystalline Properties}

Figure 2 shows the mechanical response of different ingredient combinations, including the control. The compression behavior of the control at D1 (Figure $2(a))$ is typical of solid foam, e.g., bread or a spongy pastry product of medium-to-high density [18]. The Young's modulus was $4.7 \times 10^{4} \pm 4.2 \times 10^{3} \mathrm{~Pa}$, consistent with values reported for distinct types of bread [19] [20]. The Young's modulus increased with time regardless of fat type and content, but the magnitude of the increase depended on storage conditions. For example, at D3, Young's modulus increased 3.6 times for lard-containing bread stored in a cardboard box at ambient temperature (Figure 2(b)). This growth is slower than in bakery products [19] but considerably faster than for cakes [2] [8]. At D1, the firmness of the specimens was not significantly different $(\mathrm{p}<0.05)$ regardless of

(a)
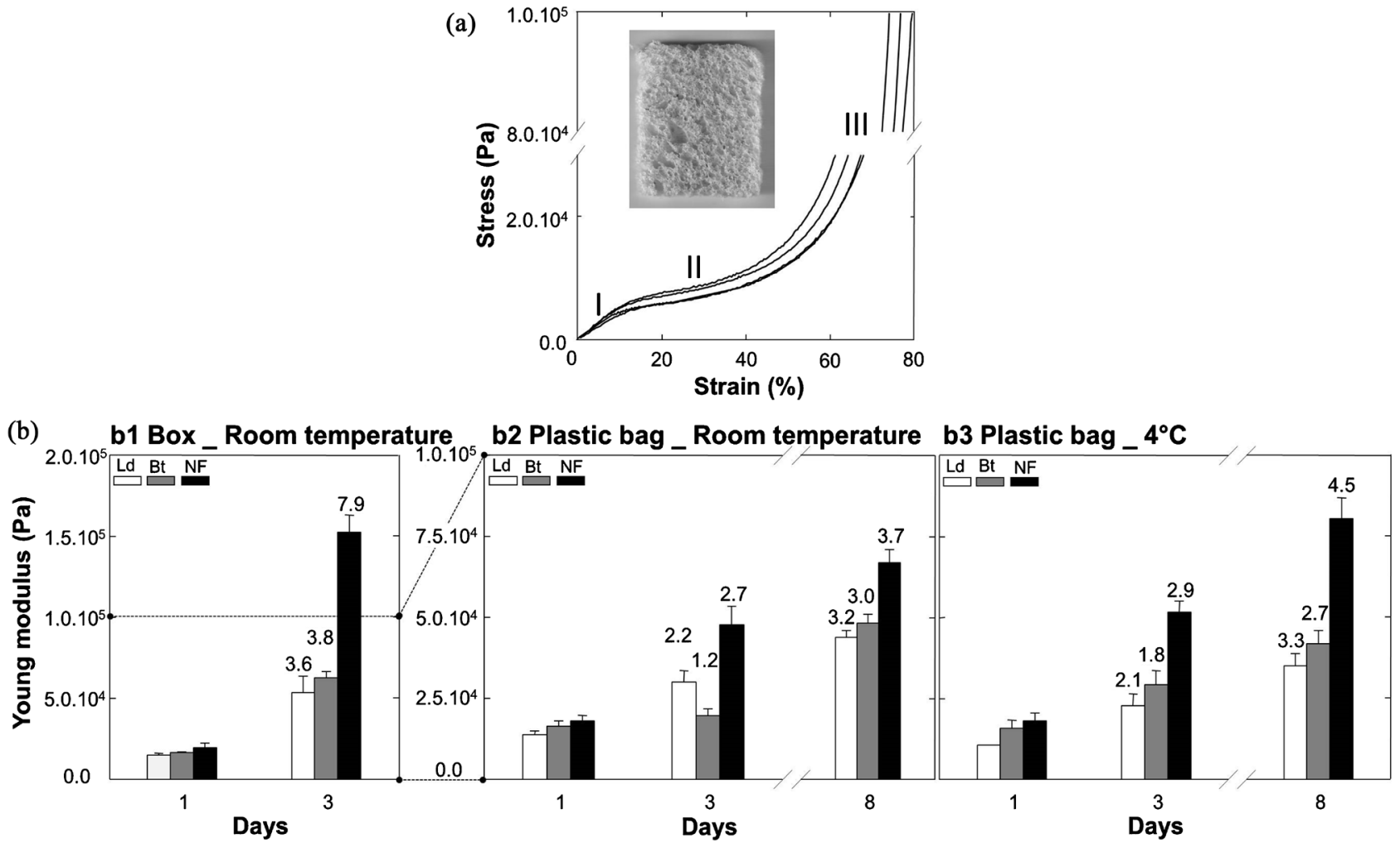

Figure 2. Typical stress-strain compression curves of "Pan de Muerto". (a) after one day of storage; (b) Young moduli of different bread samples as a function of storage time. Compression steps, I, II and III [18] for $\mathrm{n}=4$. Ld = Lard, Bt = Butter, and N.F. $=$ No Fat. Numbers over the bars for each sample indicate the magnitude of modulus increase relative to day one. 
their fat type and content (Figure 2(b)). However, hardness increased to various extents depending on storage conditions. Increases from two to four times were observed for bread with lard or butter stored in the cardboard box or plastic bag at different temperatures (Figures 2(b1)-(b3)). Bread without added fat exhibited increases from four to eight times for storage in the cardboard box and plastic bags. Such increases were the largest observed.

Fat reduced the growth in the firmness of the different specimens, especially for storage in the plastic bags regardless of temperature. This result agrees with the reported data [10]. Slight differences in firmness increase were observed between lard and butter. No direct relationships were found between water loss and stiffness increase with time for the different formulations. This result is consistent with previous reports [3].

Nevertheless, two observations can be made: 1) for storage in a cardboard box and similar moisture, bread without added fat was firmer than fat-containing bread, 2) for storage in plastic bags and despite differences of about $5 \%$ in moisture content, lard, and butter bread had similar firmness. Then, water's role in these matrices' mechanical properties and their time evolution seemed different. The chosen conditions resulted in different staling rates without finding a direct relation to moisture content.

Figure 3 shows the DSC thermographs of normal and freeze-dried-defatted crumbs for the control and the other ingredient combinations. Initially, D0, the normal crumb, exhibited only one melting endotherm between $10^{\circ} \mathrm{C}$ and $40^{\circ} \mathrm{C}$ (Figure 3(a)). This transition is ascribed to fat crystals melting because freeze-dried-defatted crumbs did not show this change at D1 and D8 (Figure $3(\mathrm{a}))$.

Butter and lard have fusion temperatures below $45^{\circ} \mathrm{C}$ [21]. In normal crumb, this transition profile evolved with time; at D8, the number of fusion peaks increased and displaced to upper temperatures (Figure 3(a)). Fat melting characteristics seemed to change with storage.

At D0, no endotherm could be observed between $40^{\circ} \mathrm{C}$ and $80^{\circ} \mathrm{C}$ (Figure 3 (a)) for the normal crumb. This behavior suggests that starch granules were gelatinized, and hence their crystalline order was lost during baking. However, at $\mathrm{D} 1$ and D8, a new main melting endotherm was observed between $35^{\circ} \mathrm{C}$ and $60^{\circ} \mathrm{C}$ (Figure 3(a)) for the normal crumb. This modification was attributed to starch retrogradation, i.e., the melting of amylopectin crystals [9] [22]. This same phenomenon was observed for the freeze-dried-defatted bread at D1 and D8. In this case, the first endotherm's disappearance due to fat removal resulted in a better defined second endotherm, Figure 3(a). Thus, different fat-melting profiles and starch retrogradation were observed under storage, which underlines these phenomena' potential roles in aging "Pan de Muerto."

Typical DSC thermograms for fat-containing, without added fat, and freeze-dried-defatted crumbs for the different storage conditions and fat type are shown in Figure 3(b1) and Figure 3(b2), respectively. The patterns of normal 

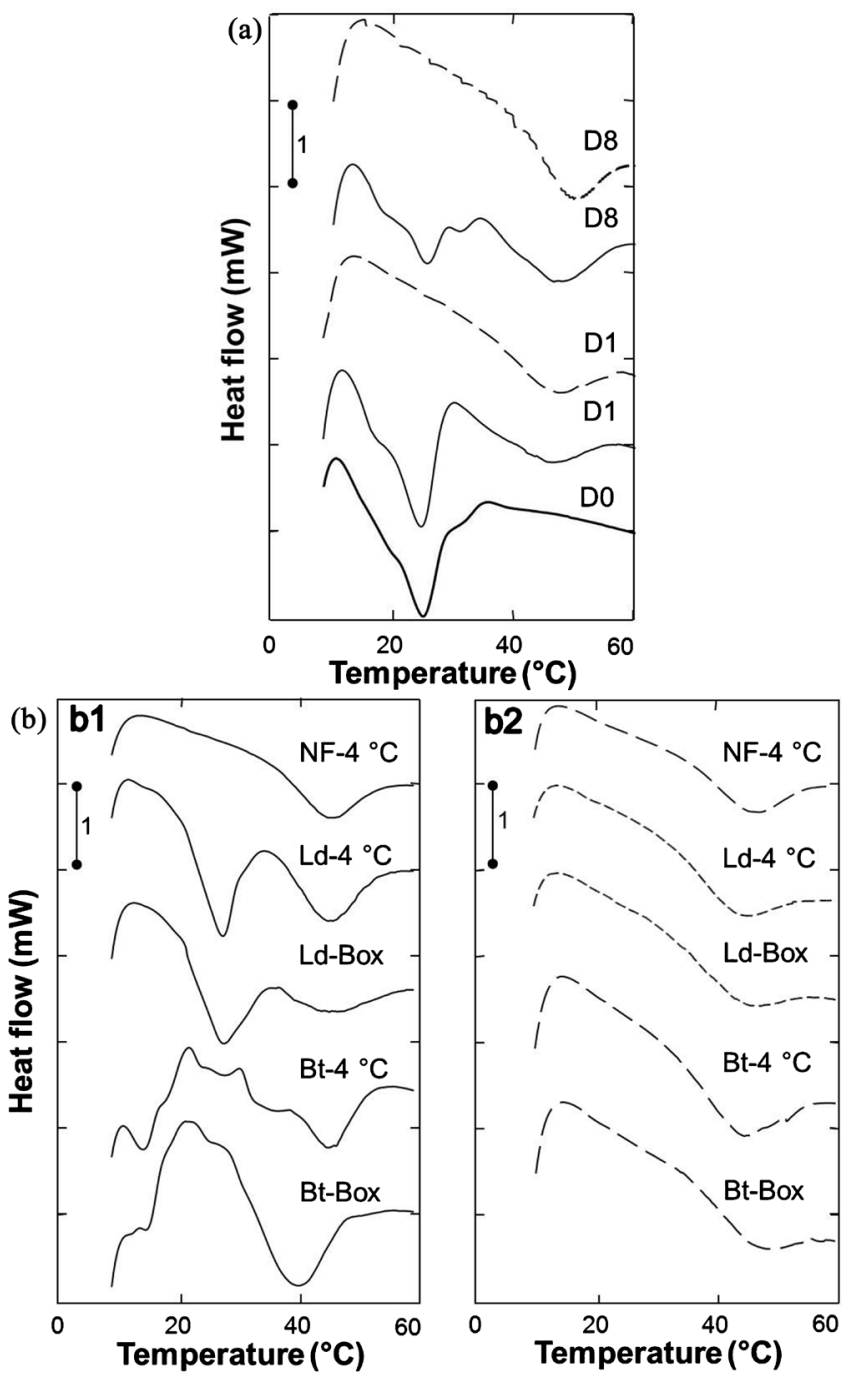

Figure 3. DSC thermograms of different specimens of "Pan de Muerto"; a: Control at D0 and after one and eight days of storage, D1, and D8, respectively; b: Bread with lard (Ld), Butter (Bt), and without fat (N.F.), after eight days of storage. Normal crumb (continuous lines) and freeze-dried-defatted crumb obtained from normal samples (discontinuous lines).

(Figure 3(b1)) and freeze-dried-defatted (Figure 3(b2)) stored at $4^{\circ} \mathrm{C}$ expose the endothermal melting of amylopectin. This behavior made it possible to identify the transitions attributed to fats in fat-containing bread in a more precise way. For example, lard-containing samples showed the main endotherm at $27^{\circ} \mathrm{C}$ $\pm 1^{\circ} \mathrm{C}$, with a transition range of $16^{\circ} \mathrm{C} \pm 1^{\circ} \mathrm{C}$, regardless of the storage conditions and time; Figure $3(\mathrm{~b} 1)$. On the other hand, in butter-containing bread, the endotherms at low temperature were hardly distinguishable; Figure 3(b1).

Samples stored in plastic bags at $4^{\circ} \mathrm{C}$ exhibited several endotherms at low temperatures. This behavior shows that only butter crystallization was highly dependent on storage temperature, 20 versus $4^{\circ} \mathrm{C}$. Similar results were shown for milk fat crystallization in cakes containing rapeseed oil and anhydrous milk fat [8]. Butter and lard are well known for their polymorphism. However, due to a 
more straightforward composition, lard crystallized in more stable crystals than butter under similar cooling conditions [21]. This difference could explain part of the results. The specimens were stored after the first cooling at room temperature; this step could have led to a more stable crystallization in lard than butter. Also, the slight impact of the storage temperature of $4^{\circ} \mathrm{C}$ on lard crystallization could be due to interactions between lard and the bread matrix that would favor a stable crystallization.

No clear evolution with time, D1 versus $\mathrm{D} 8$, of fat melting behavior could be observed compared to the control. Mixing lard with butter would lead to a new lipid phase with distinctive characteristics and behavior. In the literature, the impact of fat crystals on a prepared product has been mainly discussed for dough making and fat crystallization just after baking [10]. To the best of our knowledge, the role that several factors like the different nature, characteristics of fat crystals, and their time evolution have on the products' features has never been studied and discussed. The results obtained here highlight the potential for this type of study.

Enthalpies of the melting endotherms for amylopectin are shown in Table 1. Those for the crumb of butter-containing bread could not be separated from the melting endotherms of fat. All endotherms showed maximum temperatures of $44.5^{\circ} \mathrm{C} \pm 1^{\circ} \mathrm{C}$. Their onset and offset temperatures were $30^{\circ} \mathrm{C} \pm 1^{\circ} \mathrm{C}$ and $60^{\circ} \mathrm{C} \pm$ $1^{\circ} \mathrm{C}$, respectively, but those for the crumb of lard-containing bread were $34.5 \pm$ $0.5^{\circ} \mathrm{C}$ and $57.5^{\circ} \mathrm{C} \pm 0.5^{\circ} \mathrm{C}$, respectively. The measured enthalpies were between 0.8 and $2.0 \mathrm{~J} / \mathrm{g}$. For a similar storage time, measurements made in excess water and expressed as J/g of dry matter, enthalpies between $0.6-0.9 \mathrm{~J} / \mathrm{g}$ have been reported for cakes [9] and between $2.0-3.0 \mathrm{~J} / \mathrm{g}$ for bread [23]. The enthalpies of "Pan de Muerto" were intermediate, which is consistent with its hybrid characteristics. Composition and storage conditions had a significant impact on enthalpy. The storage in cardboard boxes limited starch retrogradation compared to storage in plastic bags; Table 1 . This effect was more critical for lard-containing than for bread without added fat except for storage at $4^{\circ} \mathrm{C}$. The presence of lard decreased the rate of starch retrogradation regardless of storage conditions.

The measured enthalpies (Table 1) and amylopectin's fusion temperatures (Figure 3(b2)) were not modified for N.F. bread, except that for plastic bags at $4^{\circ} \mathrm{C}$. The impact of fat extraction appeared to be very low. However, for lard-containing bread, the endotherm of amylopectin for freeze-dried-defatted crumb showed distinct characteristics than those observed for the normal crumb. First, their enthalpies were doubled or tripled; Table 1. Second, the temperature range of the transition was higher; $30^{\circ} \mathrm{C} \pm 1.5^{\circ} \mathrm{C}$ versus $23^{\circ} \mathrm{C} \pm 1^{\circ} \mathrm{C}$. Third, the onset and offset temperatures were displaced to lower and higher temperatures, respectively. For butter-containing bread, the sum of fat and amylopectin melting enthalpies of the normal crumb was lower than the amylopectin enthalpies of freeze-dried-defatted crumbs. It is then possible to affirm that a similar effect, i.e., increase in starch melting enthalpies, seemed to happen. 
Table 1. Enthalpies (J/g) of amylopectin melting for normal and freeze-dried-defatted crumbs of the modified formulations.

\begin{tabular}{cccccccccc}
\hline & \multicolumn{3}{c}{ Box } & \multicolumn{3}{c}{ Plastic Bag } & \multicolumn{3}{c}{ Plastic Bag } \\
& \multicolumn{1}{c}{ Room temperature } & \multicolumn{2}{c}{ Room temperature } & & $4^{\circ} \mathrm{C}$ & \\
\cline { 2 - 9 } & D1 & D3 & D8 & D1 & D3 & D8 & D1 & D3 & D8 \\
\hline Normal & & & & & & & & & \\
No lard or butter (NF) & 1.0 & 1.4 & 1.6 & 1.4 & 1.7 & 2.0 & 1.5 & 2.0 & 1.8 \\
Lard (Ld) & 0.4 & 0.6 & 0.8 & 0.7 & 1.4 & 1.7 & 0.6 & 0.7 & 1.4 \\
Butter (Bt) & 2.7 & ND & ND & ND & ND & ND & ND & ND & ND \\
Freeze-dried-defatted & & & & & & & & & \\
No lard or butter (NF) & 1.2 & 1.6 & 1.7 & 1.1 & ND & 2.0 & 0.9 & 1.9 & 2.0 \\
Lard (Ld) & 1.5 & ND & 1.8 & 1.5 & ND & 2.2 & 1.5 & ND & 2.3 \\
Butter (Bt) & 1.2 & ND & 1.4 & 1.5 & ND & 3.1 & 1.2 & ND & 2.7 \\
\hline
\end{tabular}

ND: Not Determined.

This phenomenon was observed only when fat was initially present. In other studies, crumbs were also defatted to limit the impact of fat melting on starch retrogradation quantification [9]. However, these authors do not discuss the eventual impact of defatting on their results. Therefore, it is impossible to know whether such results are due to the defatting procedure or fat removal itself. As bread without added fat did not present any significant differences, the possible effect of extraction solvent seems unlikely.

Nevertheless, it is evident that fat extraction resulted in different thermal behavior, and consequently, fat removal can explain these results. An endotherm's sharpness represents the purity of the melted crystals, and its enthalpy represents the quantity [14] [17]. Therefore, fat removal had an impact on sharpness and enthalpy. Two hypotheses could explain this result. First, the energy released during the melting of fat crystals could lead to the fusion of the less stable amylopectin crystals at lower temperatures, resulting in a sharper melting endotherm of amylopectin and a decrease of its enthalpy. Second, defatting could bring starch components closer and promote their association. However, defatting was carried out in a freeze-dried specimen with water activity $<0.02$, limiting normal crystal formation, crystal evolution, or both. Thus, defatting could result in other differences between the enthalpies of the specimens. The storage of bread in cardboard boxes resulted in less starch retrogradation, but no more apparent differences were obtained between the bread without added fat and the lard-containing bread; Table 1 .

Figure 4(a) shows the control at D0 exhibited a predominantly amorphous $\mathrm{X}$-ray profile but with peaks attributed to V-type crystals, i.e., $13^{\circ}$ and $19^{\circ}-20^{\circ}$ [17]. This result confirmed DSC observations: that is, starch was practically gelatinized during baking. Similarly, at D1 and D8 new peaks at scattering angles of $5.6^{\circ}, 15^{\circ}, 17^{\circ}, 22^{\circ}$, and $24^{\circ}$, appeared on the X-ray profile; Figure 4(a). They can 


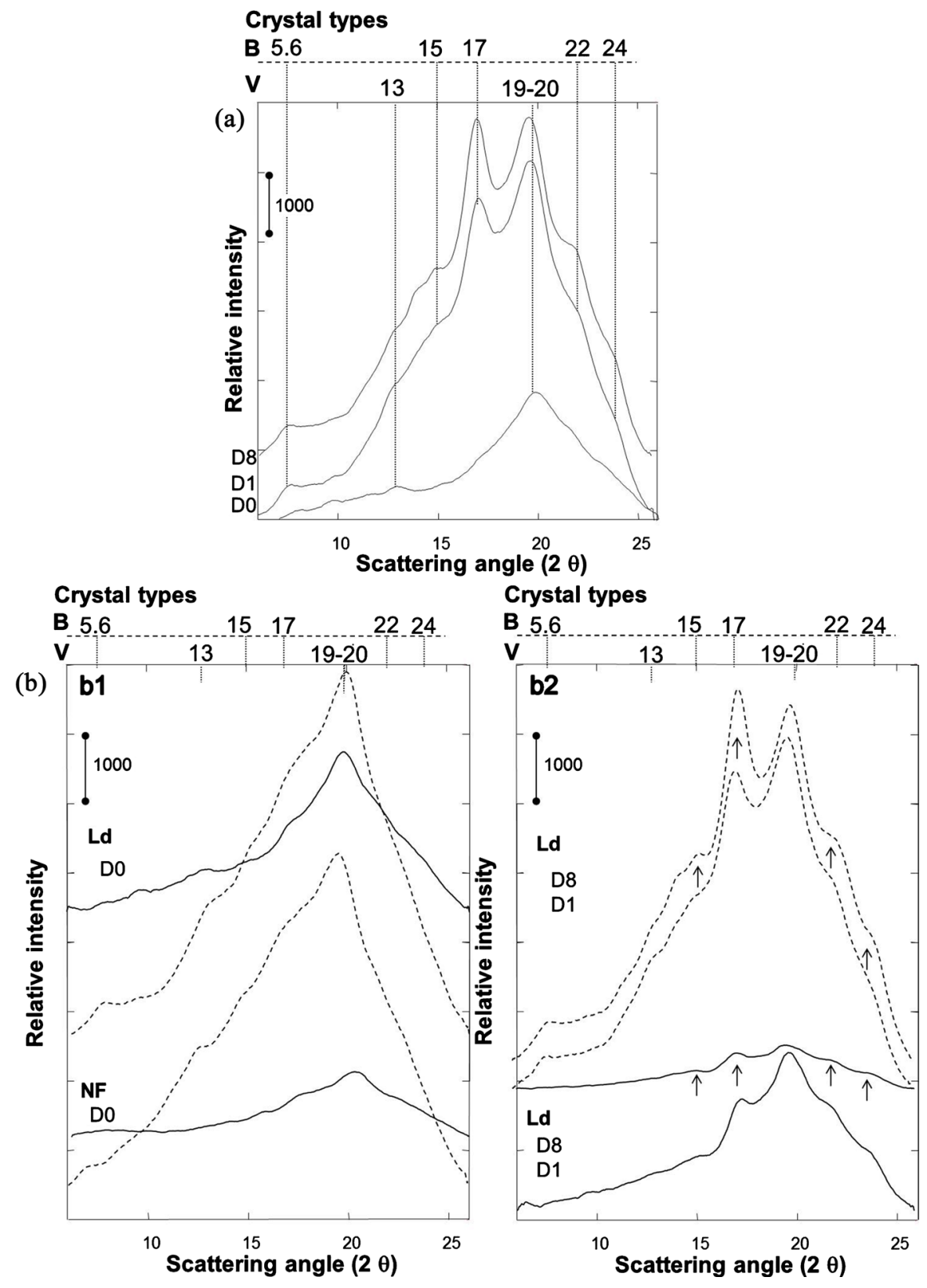

Figure 4. Normalized X-ray profiles of different specimens of "Pan de Muerto". (a) Control, (b) Added with lard (Ld), butter (Bt), and without fat (N.F.). Normal crumb (continuous lines), freeze-dried-defatted crumb (discontinuous lines) from the normal crumb. Fresh-from-the-oven (D0), one (D1), and eight (D8) days of storage. Vertical arrows show the increase in intensity between D1 and D8.

be attributed to starch crystallization during storage. They show the role of starch retrogradation [9] [22] on the aging of "Pan de Muerto". Typical X-ray diffraction patterns for normal and freeze-dried-defatted crumbs are shown in Figure 4(b). Unlike freeze-dried-defatted crumb, at D0, samples' relative intensities with different compositions were different for the normal crumb; Figure 4(b1) and Figure 4(b2). After storage, such differences were shown to depend mainly on the various bread matrices, Figure 4(a) and Figure 4(b), but not on 
their moisture content or water activity. Numerous methods exist to analyze $\mathrm{X}$-ray patterns; their differences depend on how the amorphous and crystalline areas are bounded [24] [25] [26].

Using a particular method can lead to different observations because increasing the global relative intensity on patterns can be viewed as increasing crystalline or amorphous areas [24] [26]. The significant differences in this study on the relative intensity between the different bread formulas could lead to erroneous interpretations. Therefore, the diffraction patterns analysis was focused on their peaks, particularly area and evolution, as described in Section 2.9. The X-ray patterns at D0 showed the peaks ascribed to V-type crystals; Figure 4(b). V-type crystals represent mostly amylose-lipids complexes in baked cereal products, already present in raw starch granules or formed during baking [7] [17] [27]. All the normal and freeze-dried-defatted crumbs' crystallinities were $6.0 \% \pm 1.0 \%$ and $8.0 \% \pm 1.0 \%$, respectively. The V-type crystals represented $82 \%-85 \%$ and $70 \%-$ $79 \%$ of total crystallinity, respectively. The $19^{\circ}-20^{\circ}$ peak has been ascribed to fat crystals' diffraction [8]. However, fat inclusion and the defatting process did not explain the differences in percentages of V-type crystals. Then, fat did not seem to induce more amylose-lipid complexes, an argument commonly used to describe the positive impact of fats on staling [2]. Furthermore, the presence of fat did not lead to an overestimation of V-type crystals through the diffraction of fat crystals. During storage, all the X-ray patterns of the samples evolved similarly; the peak area at $19^{\circ}-20^{\circ}$ diminished relatively, and its percentage decreased at the expense of peaks related to B-type crystals; Figure 4(a), Figure 4(b). This result is consistent with studies on starch retrogradation in rice [28] or baked products [22]. This evolution was defined by [28] as a V-type crystals metastability; the crystals would change over time into a more stable structure as B-type crystals. Nevertheless, the peak areas of V-crystals nearly did not evolve with time. Therefore, both crystals would coexist under storage [22].

The relative areas of V-type crystals were plotted versus the relative areas of B-type crystals for all crumbs analyzed; Figure 5(a). This relationship shows that starch crystals' time evolution followed a similar pattern regardless of the conditions used. All samples are well represented at all stages of this development; for example, the points corresponding to lard-containing bread stored in cardboard boxes and plastic bags at $4^{\circ} \mathrm{C}$ at $\mathrm{D} 1$ and D8. More B-type crystals are obtained with time, and each condition seemed to lead to its proper evolution; Figure 5(a). For example, storage in plastic bags at $4^{\circ} \mathrm{C}$ appeared to increase B-type crystals' rate for all the formulations; Figure 5(a).

Defatting increases the rate of the time evolution of starch crystals. A more relevant effect was observed for fat-containing bread, mainly butter. This primary effect is congruent with the data obtained in Section 3.2.; Table 1.

\subsection{Interaction between Thermal and Crystalline Properties}

The relative areas of B-type crystals were plotted versus the enthalpies of amylopectin melting; Figure 5(b). A good correlation was found between the two 

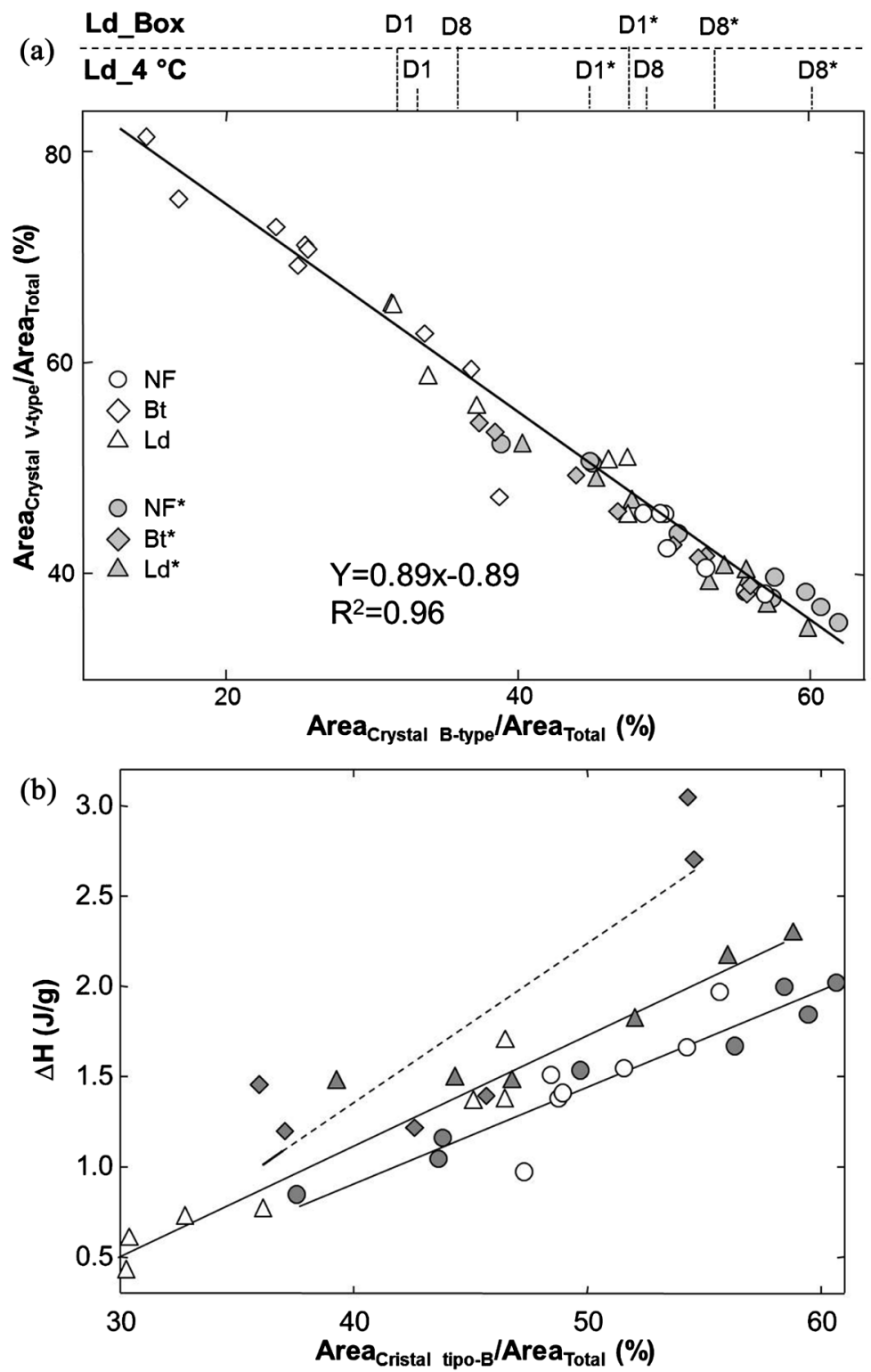

Figure 5. The relative area of B-type crystals as a function of a: the relative area of V-type crystals and b: the amylopectin's melting enthalpy. Added fat (circle), lard-containing (triangle), and butter-containing (dotted diamond) products. Normal crumb (white symbols), freeze-dried-defatted crumb (grey symbols). (a) Samples with lard (Ld) are shown for two storage conditions, in cardboard boxes (Box) and plastic bags at $4^{\circ} \mathrm{C}\left(4^{\circ} \mathrm{C}\right)$ and at two storage times; one (D1) and eight (D8) days; (b) Black continuous lines and broken lines represent correlations given by Equations (1)-(3), respectively.

parameters for bread without added fat and lard-containing bread, Equations (1) and (2), respectively, regardless of the storage conditions or crumbs examined. However, the correlation was weak for butter-containing bread, Equation (3), primarily due to the few points obtained compared to the other products. Its reliability was assessed by estimating the enthalpies per the B-type crystals percentage evaluated in the normal crumb. Most of them were negative; the correlation between data was then overestimated or inconsistent. 


$$
\begin{array}{ll}
\text { NF bread: } \Delta H=-1.2+5.4\left(\frac{\text { Area }_{\text {B-type }}}{\text { Area }_{\text {Total }}}\right) & r^{2}=0.8817 \\
\text { Lard-containing bread: } \Delta H=-1.3+6.1\left(\frac{\text { Area }_{\text {B-type }}}{\text { Area }_{\text {Total }}}\right) & r^{2}=0.9365 \\
\text { Butter-containing bread: } \Delta H=-2.2+8.9\left(\frac{\text { Area }_{\text {B-type }}}{\text { Area }_{\text {Total }}}\right) & r^{2}=0.7765
\end{array}
$$

DSC and X-ray diffraction allowed us to determine a related extent and rate of starch retrogradation. The relation found between both techniques could be discussed in two ways. First, in starch gelatinization, X-ray diffraction measures the crystalline order of starch, and DSC measures the loss of molecular order, i.e., double helices' content [29]. This consideration would mean that for a similar product, the crystals, and double helices, would increase "proportionally" during retrogradation, and their original content would define all the retrogradation process. As such, the molecular order of lard-containing bread would be initially higher than that of fat-free products.

On the other hand, amylose and amylopectin were shown to form B-type crystals of very different thermal characteristics [14]. According to our data, no differences in melting temperatures were observed, but a higher enthalpy was needed to melt crystals formed in the lard-containing product for a similar percentage of crystals. Then, the characteristics of the B-type crystals formed in each product could be different. A similar tendency stood out for butter-containing products but could not be confirmed. No matter how this result is discussed, the combination of the product's ingredients directly relates to the retrograded starch's characteristics. This result could be due to differences in starch pasting characteristics at the end of baking of bread and different distribution of the starch macromolecules into the bread matrix.

The modifications obtained from defatting reinforced this result. The points related to measurements made in freeze-dried-defatted crumbs followed the same patterns as the others. Defatting promoted starch retrogradation without modifying the characteristics of the crystal. It is most probable that modifications induced the time evolution of the starch crystals already present in the matrices, which allowed better differentiation between the different pieces of bread. As already mentioned, the different specimens' water activity in which fat was removed was lower than 0.02 . Thus, it seemed that despite the lack of free water in the product, the time evolution of crystals was possible, contrary to common findings.

\section{Conclusion}

"Pan de Muerto" was shown to be a hybrid between bakery and pastry products regarding the combination of the ingredients, characteristics as a fresh product, and staling mechanisms involved during its time evolution. The presence and type of fat used in this bread and its storage conditions allowed reaching a dif- 
ferent staling behavior not related to moisture content. Such conditions permitted the study to focus on fat crystallization and starch retrogradation. Only crystallization of butter depended on storage temperature. The presence of fat affected starch retrogradation and particularly the formed amylopectin crystals. Also, the presence of fat resulted in crystals of higher thermal stability. Storage conditions did not impact the mechanism of starch retrogradation but increase or decrease its rate. Eight days of storage time result in changes that might have some impact on popular beliefs about the shelf-life of this traditional product. Finally, the staling behavior and relative impact of different phenomena depend on the product's formula.

\section{Acknowledgements}

Thanks are due to Programa de Apoyo a la Investigación y el Posgrado (PAIP) of Facultad de Química-UNAM for partial funding (Grant 5000-9098). A. Matignon gratefully acknowledges financial support from DGAPA-UNAM (Programa de Becas Posdoctorales). The technical assistance of Mariana Ramírez-Gilly and María Cecilia Salcedo-Luna is genuinely appreciated. Our special gratitude is to Rodolfo F. Serrano-Tecante for his professional advice on breadmaking.

\section{Conflicts of Interest}

The authors declare no conflicts of interest regarding the publication of this paper.

\section{References}

[1] Gray, J. and BeMiller, J.N. (2003) Bread Staling: Molecular Basis and Control. Comprehensive Reviews in Food Science and Food Safety, 2, 1-21. https://doi.org/10.1111/j.1541-4337.2003.tb00011.x

[2] Wilderjans, E., Luyts, A., Brijs, K. and Delcour, J.A. (2013) Ingredient Functionality in Batter Type Cake Making. Trends in Food Science and Technology, 30, 6-15. https://doi.org/10.1016/j.tifs.2013.01.001

[3] Willhoft, E.M.A. (1973) Mechanism and Theory of Staling of Bread and Baked Goods, and Associated Changes in Textural Properties. Journal of Texture Studies, 4, 292-322. https://doi.org/10.1111/j.1745-4603.1973.tb00844.x

[4] Aguirre, J.F., Osella, C.A., Carrara, C.R., Sánchez, H.D. and Buera, M.P. (2011) Effect of Storage Temperature on Starch Retrogradation of Bread Staling. Starch/Staerke, 63, 587-593. https://doi.org/10.1002/star.201100023

[5] Bosmans, G.M., Lagrain, B., Ooms, N., Fierens, E. and Delcour, J.A. (2013) Biopolymer Interactions, Water Dynamics, and Bread Crumb Firming. Journal of Agricultural and Food Chemistry, 61, 4646-4654. https://doi.org/10.1021/jf4010466

[6] Gélinas, P., Roy, G. and Guillet, M. (1999) Relative Effects of Ingredients on Cake Staling Based on an Accelerated Shelf-Life Test. Journal of Food Science, 64, 937-940. https://doi.org/10.1111/j.1365-2621.1999.tb15944.x

[7] Buléon, A., Colonna, P., Planchot, V. and Ball, S. (1998) Starch Granules: Structure and Biosynthesis. International Journal of Biological Macromolecules, 23, 85-112. https://doi.org/10.1016/S0141-8130(98)00040-3 
[8] Hesso, N., Le-Bail, A., Loisel, C., Chevallier, S., Pontoire, B., Queveau, D. and Le-Bail, P. (2015) Monitoring the Crystallization of Starch and Lipid Components of the Cake Crumb during Staling. Carbohydrate Polymers, 133, 533-538. https://doi.org/10.1016/j.carbpol.2015.07.056

[9] Luyts, A., Wilderjans, E., van Haesendonck, I., Brijs, K., Courtin, C.M. and Delcour, J.A. (2013) Relative Importance of Moisture Migration and Amylopectin Retrogradation for Pound Cake Crumb Firming. Food Chemistry, 141, 3960-3966. https://doi.org/10.1016/j.foodchem.2013.06.110

[10] Pareyt, B., Finnie, S.M., Putseys, J.A. and Delcour, J.A. (2011) Lipids in Bread making: Sources, Interactions, and Impact on Bread Quality. Journal of Cereal Science, 54, 266-279. https://doi.org/10.1016/j.jcs.2011.08.011

[11] Matignon, A. and Tecante, A. (2017) Starch Retrogradation: From Starch Components to Cereal Products. Food Hydrocolloids, 68, 43-52.

https://doi.org/10.1016/j.foodhyd.2016.10.032

[12] Morris, V.J. (1990) Starch Gelation and Retrogradation. Trends Food Science Technology, 1, 2-6. https://doi.org/10.1016/0924-2244(90)90002-G

[13] Ottenhof, M.A. and Farhat, I.A. (2004) Starch Retrogradation. Biotechnology Genetic Engineering Reviews, 21, 215-228. https://doi.org/10.1080/02648725.2004.10648056

[14] Biliaderis, C.G. (1991) The Structure and Interactions of Starch with Food Constituents. Canadian Journal of Physiology and Pharmacy, 69, 60-78.

https://doi.org/10.1139/y91-011

[15] FAO (2015) FAOSTAT Commodity List-Groups. http://www.fao.org/faostat/en/\#data/QC/visualize

[16] Scanlon, M.G. and Zghal, M.C. (2001) Bread Properties and Crumb Structure. Food Research International, 34, 841-864. https://doi.org/10.1016/S0963-9969(01)00109-0

[17] Zobel, H.F. (1988) Starch Crystal Transformations and Their Industrial Importance. Starch-Stärke, 40, 1-7. https://doi.org/10.1002/star.19880400102

[18] Peleg, M., Roy, I., Campanella, O.H. and Normand, M.D. (1989) Mathematical Characterization of the Compressive Stress-Strain Relationships of Spongy Baked Goods. Journal Food Science, 54, 947-949. https://doi.org/10.1111/j.1365-2621.1989.tb07919.x

[19] Keetels, C.J.A.M., Visser, K.A., van Vliet, T., Jurgens, A. and Walstra, P. (1996) Structure and Mechanics of Starch Bread. Journal of Cereal Science, 24, 15-26. https://doi.org/10.1006/jcrs.1996.0033

[20] Lassoued, N., Delarue, J., Launay, B. and Michon, C. (2008) Baked Product Texture: Correlations between Instrumental and Sensory Characterization Using Flash Profile. Journal of Cereal Science, 48, 133-143. https://doi.org/10.1016/j.jcs.2007.08.014

[21] Campos, R., Narine, S.S. and Marangoni, A.G. (2002) Effect of Cooling Rate on the Structure and Mechanical Properties of Milk Fat and Lard. Food Research International, 35, 971-981. https://doi.org/10.1016/S0963-9969(02)00159-X

[22] Hug-Iten, S., Escher, F. and Conde-Petit, B. (2003) Staling of Bread: Role of Amylose and Amylopectin and Influence of Starch-Degrading Enzymes. Cereal Chemistry, 80, 654-661. https://doi.org/10.1094/CCHEM.2003.80.6.654

[23] Bosmans, G.M., Lagrain, B., Fierens, E. and Delcour, J.A. (2013a) The Impact of Baking Time and Bread Storage Temperature on Bread Crumb Properties. Food 
Chemistry, 141, 3301-3308. https://doi.org/10.1016/j.foodchem.2013.06.031

[24] Frost, K., Kaminski, D., Kirwan, G., Lascaris, E. and Shanks, R. (2009) Crystallinity and Structure of Starch Using Wide Angle X-Ray Scattering. Carbohydrate Polymers, 78, 543-548. https://doi.org/10.1016/j.carbpol.2009.05.018

[25] Nara, S. and Komiya, T. (1983) Studies on the Relationship between Water-Saturated State and Crystallinity by the Diffraction Method for Moistened Potato Starch. Starch-Stärke, 35, 407-410. https://doi.org/10.1002/star.19830351202

[26] Ribotta, P.D., Cuffini, S., León, A.E. and Añón, M.C. (2004) The Staling of Bread: An X-Ray Diffraction Study. European Food Research and Technology, 218, 219-223. https://doi.org/10.1007/s00217-003-0835-8

[27] Gidley, M.J. and Bociek, S.M. (1988) 13C CP/MAS NMR Studies of Amylose Inclusion Complexes, Cyclodextrins, and the Amorphous Phase of Starch Granules: Relationships between Glycosidic Linkage Conformation and Solid State 13C Chemical Shifts. Journal of the American Chemical Society, 110, 3820-3829. https://doi.org/10.1021/ja00220a016

[28] Hibi, Y., Kitamura, S. and Kuge, T. (1990) Effects on Lipids on Retrogradation of Cooked Rice. Cereal Chemistry, 67, 7-10.

[29] Cooke, D. and Gidley, M.J. (1992) Loss of Crystalline and Molecular Order during Starch Gelatinisation: Origin of the Enthalpic Transition. Carbohydrate Research, 227, 103-112. https://doi.org/10.1016/0008-6215(92)85063-6 